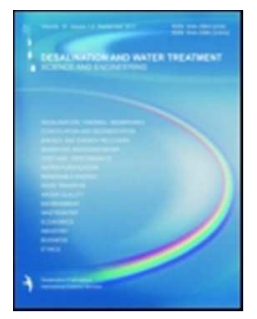

\title{
REDUCTION OF HALOACETIC ACIDS IN NATURAL SURFACE WATER BY INTEGRATED TREATMENT: COAGULATION AND MEMBRANE PROCESSES
}

\begin{tabular}{|c|c|}
\hline Journal: & Desalination and Water Treatment \\
\hline Manuscript ID & TDWT-2016-0043.R1 \\
\hline Manuscript Type: & Original Paper \\
\hline Date Submitted by the Author: & 26-Jul-2016 \\
\hline Complete List of Authors: & $\begin{array}{l}\text { SENTANA, IRENE; UNIVERSITY OF ALICANTE, Water and Environmental } \\
\text { Science Institute } \\
\text { Benraouane, Ouafa; Universite des Sciences et de la Technologie Houari } \\
\text { Boumediene Laboratoire des Sciences du Genie des Procedes Industriels } \\
\text { AIT-AMAR, Hamid; USTHB, Chemical Engineering } \\
\text { Varo, Pedro; Universitat d\'Alacant } \\
\text { Boluda-Botella, Nuria; University of Alicante, } \\
\text { Trapote, Arturo; University of Alicante, } 1 \text { University Institute of Water and } \\
\text { Environmental Sciences } \\
\text { Prats, Daniel; Universitat d\'Alacant }\end{array}$ \\
\hline Keywords: & $\begin{array}{l}\text { Nanofiltration membrane, ultrafiltration membrane, Haloacetic acids, DBP, } \\
\text { Coagulant }\end{array}$ \\
\hline
\end{tabular}

\section{SCHOLARONE ${ }^{m}$}

Manuscripts 
REDUCTION OF HALOACETIC ACIDS IN NATURAL SURFACE WATER BY INTEGRATED TREATMENT: COAGULATION AND MEMBRANE PROCESSES

\author{
Irene Sentana ${ }^{1}$, Ouafa Benraouane ${ }^{2}$, Hamid Ait-Amar ${ }^{3}$, Pedro Varó ${ }^{1}$, Nuria Boluda ${ }^{1}$, \\ Arturo Trapote ${ }^{1}$, Daniel Prats ${ }^{1}$. \\ ${ }^{1}$ Water and Environmental Science Institute, University of Alicante, P.O. Box 99, \\ 03080 Alicante, Spain. \\ 2 Laboratory Process Engineering Sciences, University of Sciences Technology \\ Houari Boumediene, USTHB, BP 32 El Alia Bab Ezzouar, 16111 Algiers. \\ 3 Department of Chemical Engineering, Faculty of Engineering Science, Saad \\ Dahlab University of Blida, Blida 09000, Alger, Algeria. \\ Corresponding author \\ Irene Sentana. Water and Environmental Science Institute, University of Alicante, \\ P.O. Box 99, 03080 Alicante, Spain. Telephone number: (+0034) 965903654. E-mail \\ address: Irene.Sentana@ua.es. Ouafa Benraouane (wafa142001@hotmail.com), \\ Hamid Ait-Amar (aitamarh@yahoo.com), Pedro Varó (pedro.varo@ua.es), Nuria \\ Boluda (nuria.boluda@ua.es) Arturo Trapote (atj@ua.es), Daniel Prats (prats@ua.es).
}

\begin{abstract}
The objectives of this research were to study the elimination of dissolved organic carbon (DOC) and the reduction in the formation of haloacetic acid potential (HAAFP) when natural water from La Pedrera reservoir was treated with a single process of coagulation or filtration membrane, and a combined process ( coagulation followed by treatment with membranes). In this research two coagulants, aluminium sulfate and polyaluminium chloride, and four membranes, two nanofiltration membranes (NF 90 and DESAL HL) and two ultrafiltration membranes (PES 5000 and PES 10000) were studied. The highest reduction in DOC was obtained when the natural water underwent the combined treatment of coagulation followed by NF90 membrane filtration. With this combined treatment the values of DOC rejection were over $82 \%$ independently of the coagulant used. For the single treatment with nanofiltration membranes, HAAFP rejection was $81 \%$ for NF 90 and $76 \%$ for Desal HL. However, a single treatment with coagulation or ultrafiltration membranes showed results for HAAFP rejection of under $35 \%$ and $26 \%$, respectively. When a combined treatment of aluminium sulfate followed by ultrafiltration with the PES 5000 membrane was used, HAAFP rejection reached values of $80 \%$ approx. These values are very similar to the results obtained from a single treatment with NF 90 but with the advantage that the flux of PES 5000 is 4,000 times the flux of the NF 90 membrane. Therefore, this treatment should be given due consideration.
\end{abstract}


KEY WORDS: Nanofiltration membrane; Ultrafiltration membrane; Haloacetic acids; DBP; Coagulant.

\section{INTRODUCTION}

It goes without saying that water is fundamental for life. Worldwide water consumption has tripled since 1950 due to the increase in population and to global economic development.

This increase in consumption and the uneven distribution of water resources worldwide, in combination with the effects of drought in certain regions, means that water is scarce. This scarcity compels us to use new sources of supply or to overexploit the existing ones. In some cases, this over-exploitation and the use of new water resources may result in a water supply for human consumption the quality of which does not meet the basic health and hygiene standards which guarantee that human consumption is safe and free from health risks using traditional methods of purification [1].

Natural waters contain varying concentrations of different organic compounds. The composition of natural organic matter (NOM) present in water depends on its place of origin and on seasonal variations. NOM is formed by a large number of compounds from low molecular weight hydrophilic acids, carbohydrates, proteins and amino acids to higher molecular weight compounds such as humic substances. Most NOM in rivers and lakes is made up of humic acids (HA) and fulvic acids (FA). These substances act as precursors of various by-products generated during the disinfection processes, such as haloacetic acids (HAAs), trihalomethanes (THMs), haloacetonitriles (HANs) and haloketones (HKs).

The most commonly used chemical products for disinfecting water are chlorine, chloramines, chlorine dioxide and ozone. When the water contains organic substances, this disinfection process has the disadvantage of generating chlorination disinfection by-products (DBPs) [2]. The formation of these DBPs in drinking water occurs when the disinfectant (usually chlorine) reacts with NOM and/or bromide/iodide present in the water. The presence of DBPs in water and their effects have been widely addressed in research ever since their adverse health effects were discovered.

The characteristics of the organic matter affect the formation of chlorination byproducts. NOM can be fractionated into hydrophobic or hydrophilic fractions. Some research indicates that during chlorination the hydrophilic fraction of NOM is mainly 
what enhances the formation of THMs while the hydrophobic fraction is the predominant agent in the formation of HAAs [3].

There are nine different types of HAAs: monochloroacetic acid (MCAA), dichloroacetic acid (DCAA), trichloroacetic acid (TCAA), monobromoacetic acid (MBAA), dibromoacetic acid (DBCAA), bromochloraacetic acid (BCAA), bromodichloroacetic acid (BDCAA), dibromochloro acetic acid (DBCAA) and tribromoacetic acid (TBAA).

As regards HAAs, studies with laboratory animals have concluded that exposure to these types of acid in drinking water may contribute to the development of some cancers, and to an increase in the number of abortions in humans [4]. The United States Environmental Protection Agency (USEPA) classifies only two types of HAAs as being potentially carcinogenic. DCAA has been classified as a probable human carcinogen, while TCAA only as a possible human carcinogen [5]. Studies on DCAA have shown the formation of liver tumours in rats and mice exposed to high concentrations of this acid in their drinking water. Some studies indicate that in tests with mice, DBAA contributes to the development of liver and lung tumours, while in tests with rats, TCAA causes damage to the DNA of mammalian cells and chromosomal abnormalities, as well as malformations in the cardiovascular and renal systems. [6].

Nowadays, various laws are in place to control the presence of disinfection byproducts in water fit for human consumption. In general terms, most of the regulations specify the maximum concentration of THMs allowed, but fewer countries or states regulate the concentrations of other by-products such as HAAs. Currently, both Spanish and European legislation only regulate the presence of THMs, setting the value of the total sum of chloroform (CF), bromodichloromethane (BDCM), chlorodibromomethane (CDBM) and bromoform (BFM) below $100 \mu \mathrm{g} / \mathrm{L}$ [7]. Conversely, in the United States of America, in addition to a more restrictive maximum concentration value of THM, less than $80 \mu \mathrm{g} / \mathrm{L}$, the maximum concentration of $\mathrm{HAA}_{5}$ is set at $60 \mu \mathrm{g} / \mathrm{L}$. As regards the maximum concentration of $\mathrm{HAA}_{5}$ in drinking water, the Guidelines for Canadian Drinking Water Quality recommend a maximum acceptable concentration of $80 \mu \mathrm{g} / \mathrm{L}$, whereas the guidelines of the World Health Organization (WHO) set a maximum concentration reference of $50 \mu \mathrm{g} / \mathrm{L}$ for DCAA, $20 \mu \mathrm{g} / \mathrm{L}$ for MCAA and $200 \mu \mathrm{g} / \mathrm{L}$ for TCAA.

Because quality standards are increasingly demanding, and studies on the harmful effects on health of ingesting water contaminated with HAAs have proven their toxic effects, it is likely that in the near future government regulations limiting the concentration of HAAs in water will set more stringent values. 
In order to reduce the formation of HAAs, it is important to decrease the concentration of dissolved organic carbon (DOC) in water prior to its chlorination. Among the techniques used to remove organic substances in water are: biological degradation, coagulation/flocculation activated carbon adsorption, ion exchange, membrane filtration and oxidation [8, 9].

Conventional treatments using coagulation/flocculation are currently the most frequently used for water purification in cities due to their low cost and good results in the removal of organic matter. These treatments are being combined in recent years with filtration, ultrafiltration and nanofiltration techniques.

Ultrafiltration and nanofiltration technologies for the reduction of NOM in water have been widely studied with different membranes and natural waters of different characteristics. Although the reduction in NOM using these membranes is high for synthetic waters, when natural waters are filtered the reduction in NOM is lower due to the fact that the molecular size of DOC in natural water is generally lower than in synthetic water [10,11].

In the last decade, research has focused on applying combined treatments of membrane filtration and other techniques such as coagulation or the use of resins.

Recent studies focus mainly on the analysis of membrane fouling and on improving coagulation treatments to reduce this fouling. Xu et al. (2015) [12] conducted a study with synthetic waters on the impact of organic coagulant aid on purification performance and membrane fouling in a coagulation/ultrafiltration hybrid process. Feng et al. (2015) [13] studied ultrafiltration membrane fouling with different aluminium coagulants on synthetic waters and ultrafiltration membranes of $100 \mathrm{kDa}$ MWCO, as well as their efficiency in DOC removal. Wang et al. (2012) studied the effect of the size and structure of flocs on synthetic water following a combined coagulation/ultrafiltration process to remove precursors of disinfectant products with $30 \mathrm{kDa}$ membranes at various $\mathrm{pH}$ and ferric coagulant concentrations [14]. Bergamasco et al. (2011) conducted a study with natural waters from a river in Brazil using coagulation/flocculation/ultrafiltration systems with ceramic membranes, observing that surface water coagulated with aluminium sulfate produced less membrane fouling than natural waters or those coagulated with chitosan [15].

Coagulation/flocculation on natural water followed by ultrafiltration or nanofiltration treatments with a view to observing their effects on the formation of HAAs, has not been extensively researched, since most studies focus on synthetic waters and their effect on THM using higher molecular weight membranes as compared to those used in the present study. For this reason, this research was carried out using water from the Mediterranean Basin of Spain, to study the effect of coagulation followed by 
ultrafiltration or nanofiltration on the removal of DOC and the formation of HAAs when this treated water was subjected to a chlorination treatment. Moreover, the effect produced by the type of coagulant (polyaluminium chloride and aluminium sulfate) and four different membranes, two ultrafiltration (PES 5000 and PES 10000) and two nanofiltration (NF 90 and DESAL HL), was also studied. For each coagulant and each membrane type, their application in the purification of natural water was examined with the aim of introducing HAA formation potential (HAAFP), when either a single membrane filtration or coagulation treatment, or combined treatments (coagulation followed by membrane filtration) are used.

\section{EXPERIMENTS}

\subsection{Feed water}

Natural water from La Pedrera reservoir was used for this research. This reservoir is located in Southeastern Spain, in the province of Alicante, and is used as the water supply for several municipalities such as Orihuela.

Reservoir water samples were initially screened using a Wattman GF/C fiberglass filter of $0.45 \mu \mathrm{m}$ pore size to remove undissolved organic matter. The characterization of the reservoir water was carried out by determining the concentration of dissolved organic carbon (DOC), specific UV absorbance (SUVA), pH and conductivity. Values obtained from this characterization are shown in Table 1.

Table 1: Feed water characteristics

\begin{tabular}{|l|c|c|}
\hline \multicolumn{2}{|c|}{ La Pedrera reservoir water } & \\
\hline \multicolumn{1}{|c|}{ Parameters } & Range & Standard deviation \\
\hline $\mathrm{pH}$ & 7.7 & 0.12 \\
\hline Conductivity $(\mu \mathrm{S} / \mathrm{cm})$ & 808 & 16 \\
\hline DOC $(\mathrm{mg} / \mathrm{L})$ & 4.5 & 0.31 \\
\hline UV254 $\left(\mathrm{cm}^{-1}\right)$ & 0.0337 & 0.0011 \\
\hline SUVA $\left(\mathrm{L} \mathrm{m}^{-1} \mathrm{mg}^{-1}\right)$ & 0.75 & -- \\
\hline
\end{tabular}

The molecular weight distribution is presented in figure 1. 


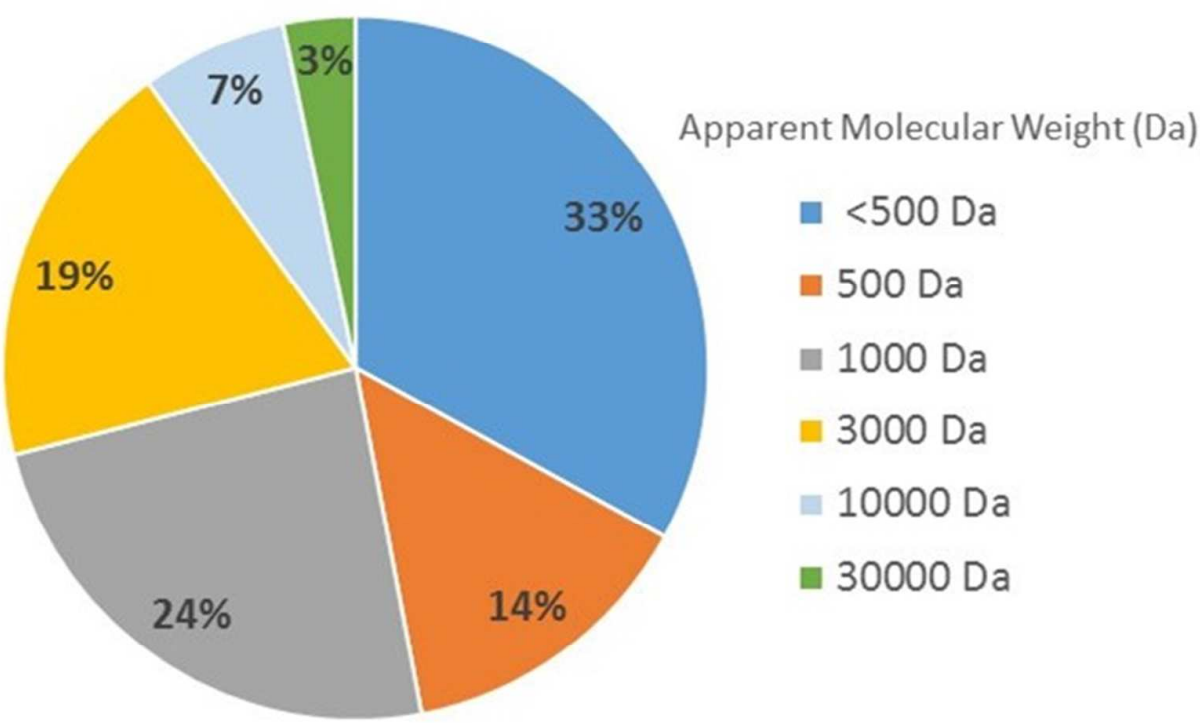

Fig. 1. Apparent molecular weight distribution of La Pedrera reservoir water (mass percentage).

The water used in this study presents low values of organic matter, and the percentage of organic matter with an apparent molecular weight under $500 \mathrm{Da}$ is $47 \%$ approx. The SUVA value of water under $3 \mathrm{~L} /(\mathrm{m} \mathrm{gC})$ suggests that the DOC is primarily composed of non-humic materials and the organic matter is relatively hydrophilic [16].

\subsection{Coagulants}

Two coagulants were selected for our study: Aluminium sulfate $\mathrm{Al}_{2}\left(\mathrm{SO}_{4}\right)_{3} 18 \cdot \mathrm{H}_{2} \mathrm{O}$ $\left(\mathrm{Al}_{2}\left(\mathrm{SO}_{4}\right)_{3}\right)$ and Polyaluminium chloride (PAC). All the coagulants used had analytical grade. $\mathrm{Al}_{2}\left(\mathrm{SO}_{4}\right)_{3}$ was obtained from Normapur Prolabo, Spain, and PAC was purchased from Kemiro Iberica, Spain.

\subsection{Membranes}

Two nanofiltration membranes were used in this research: NF 90 and DESAL HL, produced by Dow Chemical and GE Osmonics respectively, as well as two ultrafiltration membranes, PES 5000 and PES 10000, supplied by GE Infrastructure Water and Process Technology. General information about the membranes is shown in Table 2. 
Table 2. Properties of NF membranes tested.

\begin{tabular}{|c|c|c|c|c|}
\hline Membrane & NF 90 & DESAL HL & PES 5000 & PES 10000 \\
\hline Material $^{\mathrm{a}}$ & Polyamide TF & $\begin{array}{c}\text { Polypiperazine } \\
\text {-based }\end{array}$ & Polyethersulfone & Polyethersulfone \\
\hline Model & $\begin{array}{c}\text { FILMTEC }^{\text {TM }} \\
\text { NF90-400/34i }\end{array}$ & DESAL HL-51 & Biomax TM & Biomax TM \\
\hline $\mathrm{MWCO}^{\mathrm{a}}$ & 200 & $150-300$ & 5000 & 10000 \\
\hline $\begin{array}{c}\text { Water } \\
\text { permeability } \\
\left(\mathrm{m}^{3} / \mathrm{s} \cdot \mathrm{m}^{2} \mathrm{kPa}\right)^{\mathrm{b}}\end{array}$ & $2.4 * 10^{-8}$ & $2.8^{*} 10^{-8}$ & $\begin{array}{l}0.100^{*} 10^{-3}- \\
0.116^{*} 10^{-3}\end{array}$ & $\begin{array}{l}0.350^{*} 10^{-3}- \\
0.400 * 10^{-3}\end{array}$ \\
\hline Contact angle $\left({ }^{\circ}\right)$ & $54^{\circ}$ & $52^{\circ}$ & $50^{c}$ & $50^{\mathrm{C}}$ \\
\hline $\begin{array}{c}\text { Zeta Potential } \\
(\mathrm{mV})(\mathrm{pH} 7)\end{array}$ & $-24.9^{b}$ & $-14.2^{b}$ & $-5^{c}$ & $-8^{c}$ \\
\hline
\end{tabular}

a Information provide by manufacturer

b Estimated in this study

c [17]

\subsection{Experimental procedure}

\subsubsection{Coagulation experiment}

Initially, for each coagulant, a series of experiments was carried out to determine the optimum concentrations, $\mathrm{pH}$ values and stirring speed to achieve maximum reduction in DOC and turbidity. The coagulation experiments were operated by jar test apparatus (Lovibond ET 740). The coagulation procedure was carried out in 4 steps: 1. Rapid mix at $250 \mathrm{rpm}$ for $30 \mathrm{~s}$ to create a uniform sample; 2 . Coagulant of a specific dosage was added, and mixed at $250 \mathrm{rpm}$ for $120 \mathrm{~s}$; 3 . Slow mixing speed for $15 \mathrm{~min}$ to allow the particles to clump together; 4 . Solution was left to settle for $20 \mathrm{~min}$. After sedimentation, the supernatant was carefully withdrawn from about $2 \mathrm{~cm}$ below the surface for analysis. The turbidity, DOC and UV absorbance at $254 \mathrm{~nm}$ was measured for each sample. A dosage of $12 \mathrm{mg} / \mathrm{L}$ of $\mathrm{Al}$ for $\mathrm{PAC}$ and $15 \mathrm{mg} / \mathrm{L}$ of $\mathrm{Al}$ for $\mathrm{Al}_{2}\left(\mathrm{SO}_{4}\right)_{3}$ was considered optimum.

\subsubsection{Coagulation-Membrane filtration process}

Once the optimum dosage and process characteristics for each coagulant were determined as a result of the previous discontinuous assays described above, the rest of the coagulation experiments were performed using an experimental set-up allowing continuous testing. The experimental set-up used to perform the continuous experiments was specifically designed for this study (Figure 2). Two distinct phases were involved in the afore-mentioned experimental set-up, the first phase being where the process of coagulation and decantation (tanks $B$ and $C$ ) occured. The coagulant was dosed from tank $A$ by a peristaltic pump $E$. The supernatant obtained in the settling tank $C$ fell by gravity to reservoir tank $D$. Filtration treatment followed from tank $\mathrm{D}$, after adjusting the $\mathrm{pH}$ to 7.0 . 
In the second phase (after adjusting the $\mathrm{pH}$ to 7.0), water was pumped from tank $\mathrm{D}$ (8L) through a gear pump, brand MICROPUMP model 200.15, to the membrane filtration module. The brand of the membrane filtration module is Rayflow $\circledast$. It comprises two rectangular methacrylate plates in which two $77 \times 174 \mathrm{~mm}$ flat membranes are introduced, thus achieving a total membrane filtration area of 26,800 $\mathrm{mm}^{2}$. Two different feed streams were obtained in the filtration module: permeate and retentate. Valve $G$ in the retentate stream controlled the pressure of the system. The operational pressure with nanofiltration membranes was kept at $300 \mathrm{kPa}$, whereas ultrafiltration membranes were kept at $150 \mathrm{kpa}$. For each experiment, the permeate flow rate was determined and samples were removed periodically for analysis. Both permeate line $\mathrm{I}$ and retentate line $\mathrm{J}$ were reintroduced into tank $\mathrm{D}$. At all times the system pressure and the water temperature were controlled through sensors. Values of DOC, UV $254 \mathrm{~nm}$, conductivity, turbidity, pH, and HAAFP were determined from the extracted permeate.

Prior to the process of coagulation/ultrafiltration with natural water from the reservoir at La Pedrera, the conditioning of the new membranes was accomplished by flow determination with pure water until this flow was constant. Afterwards, the experiment was carried out with natural water for 28 hours. Once the experiment with natural water was finished, a third experiment with distilled water was conducted to determine the degree of irreversible fouling. This was done by means of a basic membrane wash.

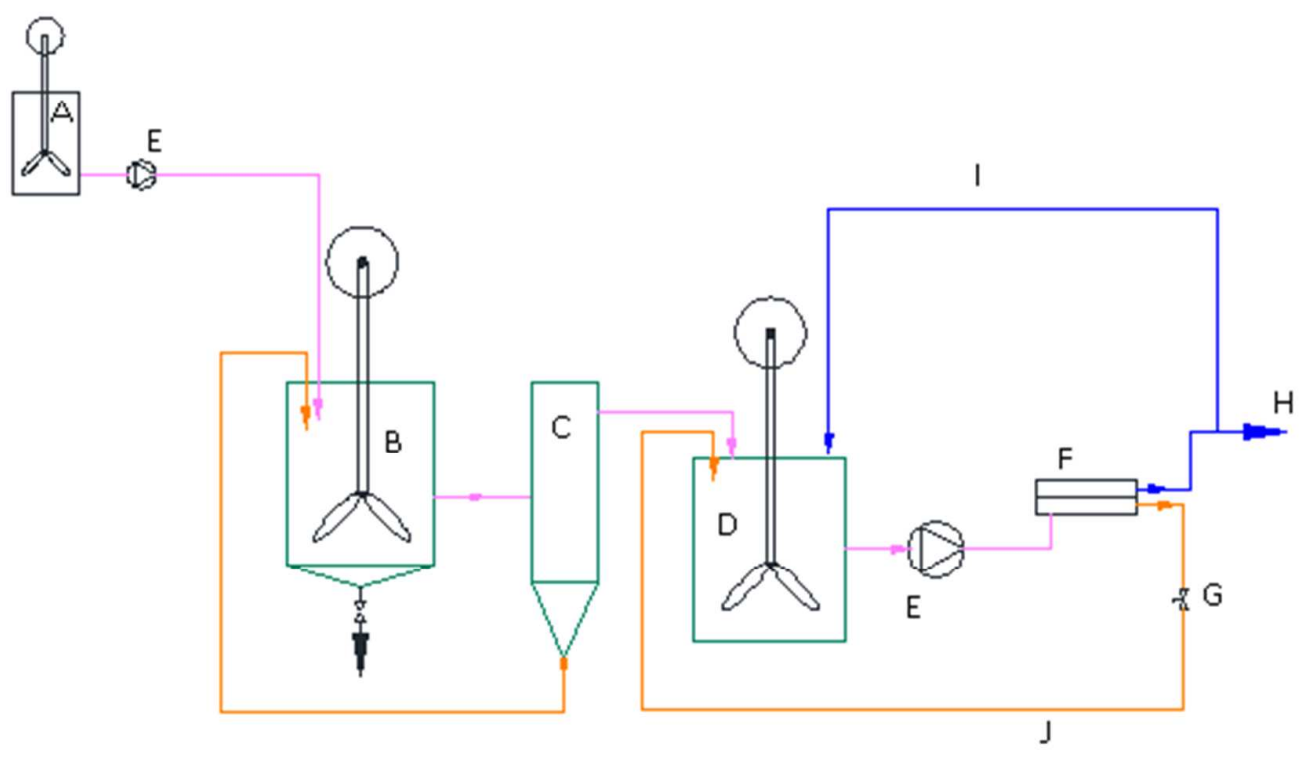

Fig. 2. Schematic stream diagram of the experimental process. A coagulant tank; B Coagulation tank; C Sedimentation tank: D supernatant tank; E pump; $F$ membrane module; $\mathrm{G}$ valve; $\mathrm{H}$ permeate; I recirculation of permeate; J Concentrate. 


\subsection{Analytical methods}

The measurement of dissolved organic carbon (DOC) was obtained using a Shimadzu TOC-5000 analyser, with a detection limit of $4 \mu \mathrm{g} / \mathrm{L}$. Ultraviolet absorbance (UV) was measured with a UV/VIS spectrophotometer (Shimadzu UV-1800) at a wavelength of $254 \mathrm{~nm}$, previously adjusting the $\mathrm{pH}$ of the solutions to 7.0 by adding $\mathrm{NaOH}$ or $\mathrm{HCl}$ to the samples. The specific ultraviolet absorbance (SUVA) was determined as the $\mathrm{UV}^{*} 100 / \mathrm{DOC}\left(\mathrm{Lm}^{-1} \mathrm{mg}^{-1}\right)$ ratio. Conductivity and $\mathrm{pH}$ were determined using a CM35 Crison conductimeter and a $\mathrm{pH}$ meter 20+Crison, respectively. The turbidity was measured using a turbidimeter (Hach 2100P Co., US).

The apparent molecular weight (MW) distribution of the natural water was determined by means of sequential membrane filtration through membranes of decreasing molecular weight cut-off (MWCO). Source waters were fractioned in a 64 $\mathrm{mm}$ diameter stirred cell (model 8200 , Amicon, Beverly, MA) by means of a series of regenerated cellulose acetate UF membranes (Millipore YM30, YM10, YM3 and YM1) of 30000, 10000, 3,000 and 1,000 Da nominal MWCO, respectively, and a cellulose acetate UF membrane (Millipore YC05) of 500 Da nominal MWCO, while bearing in mind that parameters such as the $\mathrm{pH}$, ionic strength, type of membrane, pressure and calibration might affect the MW distribution as determined using this method [18].

To determine the potential formation of the different disinfection by-products, prechlorination was performed following the 5710B "Standard Methods for the Examinations of Water and Wastewater" method of chlorination with some modifications. $20 \mathrm{mg} / \mathrm{L}$ of $\mathrm{Cl}_{2}$ was used and the reaction was maintained under the conditions described in the standard method, with the reaction lasting 72 hours. After this time, the reaction was stopped with a reducing solution of $\mathrm{NH}_{4} \mathrm{Cl}$ at a concentration of $40 \mathrm{mg} / \mathrm{mL}$ to prevent some DBPs from decomposing [19].

The HAAs formed after chlorination were determined by the EPA 552.2 method, including liquid-liquid extraction, derivation and gas chromatography with electron capture detection (GC/ECD). The patterns used for identification were obtained from Absolute Standards, INC. (EPA Method 552 Haloacetic acids, Methyl Derivatives, 100 $\mu \mathrm{g} / \mathrm{ml}$ in Methyl Tertiary Butyl Ether (MTBE). From the concentrated patterns, other patterns were developed using dilutions of MTBE and adding 1,2-dibromopropane as an internal standard (IS). Once the HAAs were extracted, the compounds were quantified with the GC/ECD method, using a DB-5MS column (Agilent J\&W Scientific, USA) with a length, inner diameter and film thickness of $30 \mathrm{~m}, 0.322 \mathrm{~mm}$ and $1.00 \mu \mathrm{m}$, respectively. The ramp had the following characteristics; initial temperature of $40^{\circ} \mathrm{C}$ for 4 minutes; subsequently, the temperature was increased from $40^{\circ} \mathrm{C}$ to $200^{\circ} \mathrm{C}$ at a rate of $5^{\circ} \mathrm{C} / \mathrm{min}$. The gas flow carrier used was helium $(1.8 \mathrm{ml} / \mathrm{min})$. The injector operated at 
a service temperature of $200^{\circ} \mathrm{C}$, while the detector temperature was kept at $260^{\circ} \mathrm{C}$. Method detection limits (MDL) for each HAA species were calculated from the standard deviation of the mean concentrations of three replicate analyses of $0.5 \mu \mathrm{g} / \mathrm{L}$ HAA standards. The corresponding MDLs for the HAAs: MCAA, MBAA, DCAA, TCAA, and DBCAA were $0.5,0.6,0.4,0.8$ and $0.8 \mu \mathrm{g} / \mathrm{L}$, respectively.

\section{RESULTS AND DISCUSSION}

\subsection{Effect of single treatment in removing natural organic matter}

Figure 3 shows the DOC removal rates for the natural water of La Pedrera reservoir having undergone a single treatment of coagulation or membrane filtration for each coagulant and membrane studied. Coagulation experiments shown here were carried out for the optimum doses of concentration, speed and $\mathrm{pH}$ obtained for each coagulant as had been previously established in this research. With a single treatment, the best DOC removal efficiencies were obtained with nanofiltration membranes, and specifically, for the NF 90 membrane followed by the DESAL HL membrane, where yields of $66 \%$ and $50 \%$, respectively, were achieved. Significantly lower values were obtained with ultrafiltration membranes attaining only 14\% for the PES 5000 membrane and $4 \%$ for the PES 10000 membrane. Among other factors, these low values achieved with the ultrafiltration membranes are due to the fact that the natural water from La Pedrera reservoir has a distribution of molecular weights lower than $1000 \mathrm{Da}$, as shown in Figure 1.

Coagulation treatment with similar DOC removal results are obtained when coagulant $\mathrm{Al}_{2}\left(\mathrm{SO}_{4}\right)_{3}$ and $\mathrm{PAC}$ are used, reaching values of $26 \%$ and $31 \%$ approx., respectively. The optimum dose of PAC coagulant used was lower than the dose used for $\mathrm{Al}_{2}\left(\mathrm{SO}_{4}\right)_{3}$ with $12 \mathrm{mg} / \mathrm{L}$ and $15 \mathrm{mg} / \mathrm{L}$ of $\mathrm{Al}$ values, respectively. For the same dose of $\mathrm{Al}$ with each coagulant, coagulation with PAC generally showed higher yields in the coagulation/flocculation process with regard to the study of parameters such as UV254, DOC and turbidity [20]. The best yields of organic matter removal with PAC are due to the fact that in solutions with pre-hydrolysed coagulants such as PAC, polymer species with high positive charges are more frequent amongst hydrolysis products than in nonpre-hydrolysed coagulants such as $\mathrm{Al}_{2}\left(\mathrm{SO}_{4}\right)_{3}$. Even though the mechanism for removing organic matter is the same in both cases, it is slightly more responsive to the size of the hydrolysis products of PAC, since the probability of collision with the organic colloid is greater. Furthermore, Yang et al. (2010) indicate that the Zeta potential of the flocs formed when PAC is used is higher and, therefore, has a higher charge neutralization power than when $\mathrm{Al}_{2}\left(\mathrm{SO}_{4}\right)_{3}$ is used as coagulant [21]. Zheng et al. (2015) 
[22] applied coagulation using a dosage of aluminium of between 15-14 mg/L. DOC rejection of between $20 \%-26 \%$ was obtained when natural water from the Simcoe river (Southern Ontario, Canada), were used. In their revision of the global process of coagulation to reduce organic matter in natural waters, Matilainen et al. (2010) [23] concluded that treatment with pre-hydrolyzed aluminium coagulants was more efficient than with the aluminium-based coagulant $\left(\mathrm{Al}_{2}\left(\mathrm{SO}_{4}\right)_{3}\right.$. De la Rubia et al. (2008) [18] obtained a DOC removal efficiency of $74 \%$ approx. when natural waters were filtered using the NF 90 membrane, and 56\% for THM reduction. These results are in line with the findings of the experiments of this research.

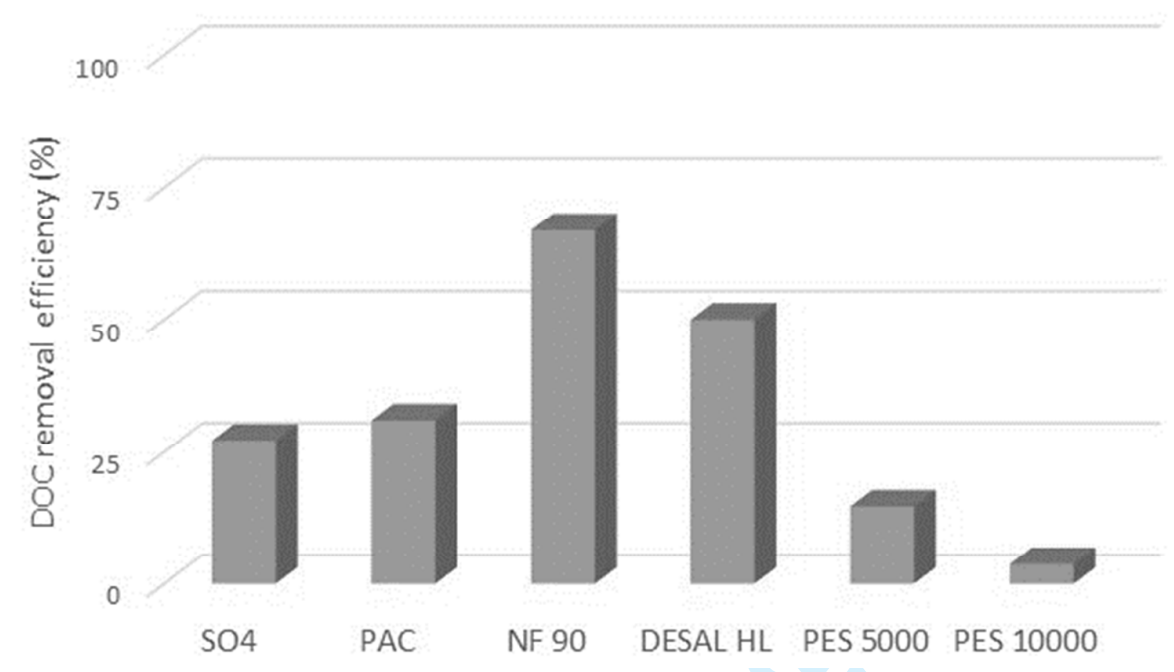

Fig. 3. Effect of single treatment on DOC removal efficiency (\%). Aluminiun sulphate coagulant $\left(\mathrm{SO}_{4}\right), \mathrm{FeCl}_{3}$ /polyaluminium chloride (PAC).

\subsection{Effects of combined treatment in the removal of natural organic matter}

Figures 4 and 5 show the percentage of DOC reduction in combined treatments with each coagulant and with nanofiltration and ultrafiltration membranes.

As evidenced in these graphs, all combination treatments enhance the reduction in dissolved organic matter in water although the reduction rates are not equally significant in all cases.

The best yields of organic matter removal are obtained for the combined treatment of coagulation and nanofiltration with NF 90 membranes (figures 4 and 5), where similar 
reduction rates of $85 \%$ and $83 \%$ for coagulation with $\mathrm{Al}_{2}\left(\mathrm{SO}_{4}\right)_{3}+\mathrm{NF} 90$ and $\mathrm{PAC}+\mathrm{NF} 90$, respectively, are achieved, showing no significant differences among the coagulants used. Combined treatment in comparison to single treatment with the NF 90 membrane alone, means an improved DOC reduction of approximately $17 \%$.

Worse DOC removal efficiencies are obtained with the DESAL HL membrane compared to those obtained with the NF 90 membrane for combined treatment with coagulation and nanofiltration. In the case of combined use of coagulant $\mathrm{Al}_{2}\left(\mathrm{SO}_{4}\right)_{3}$ with DESAL HL membrane, yields reach 64\% (figure 4) while those achieved with PAC+ DESAL HL (figure 5 ) reached only $51 \%$. In the latter case, the yield can be improved with a combined treatment but to a lesser extent than with the use of the NF 90 membrane.

By adding coagulant, there was a partial reduction in organic material with some coagulant particles remaining in solution. These particles may have stuck to organic particles, neutralizing their charge and were more easily retained by the nanofiltration membranes. This retention is also greater because the NF 90 membrane charge is lower than the charge of the DESAL HL membrane.

For the combined treatment of coagulation followed by ultrafiltration, the best yields are obtained when $\mathrm{Al}_{2}\left(\mathrm{SO}_{4}\right)_{3}$ is used as coagulant followed by ultrafiltration with the PES 5000 membrane where a yield of $42 \%$ is reached, and $39 \%$ for the PES 10000 membrane (figure 4). When compared to ultrafiltration treatment alone, a $28 \%$ improvement was achieved for PES 5000 and 35\% for PES 10000. This improvement is due, on one hand, to the organic material removed during coagulation treatment and, on the other hand, to the fact that the organic matter remaining in suspension may have partially stuck to the coagulant or other molecules, or may be to some extent neutralized, and, therefore, has a less negative overall charge and is more easily retained by ultrafiltration membranes. For synthetic waters coagulated with Poly-ferric chloride (PFC), Wang et al. (2012) [24], obtained a DOC rejection of $20 \%$ approx. This value increased to $35 \%$ when a membrane filtration with polyvinylidene fluoride membranes with a molecular weight of $300 \mathrm{kDa}$ was applied after coagulation. Xiangli et al. (2008) [25] obtained better DOC rejection results, when coagulation with PAC followed by ultrafiltration process with a hollow fibre membrane was used, as opposed to when $\mathrm{FeSO}_{4}$ was used as coagulant. Feng et al. (2015) [13] studied DOC removal efficiency with different aluminium coagulants on synthetic waters followed by ultrafiltration membrane $(100 \mathrm{kDa})$, achieving a DOC removal efficiency of $50 \%$ approx. 


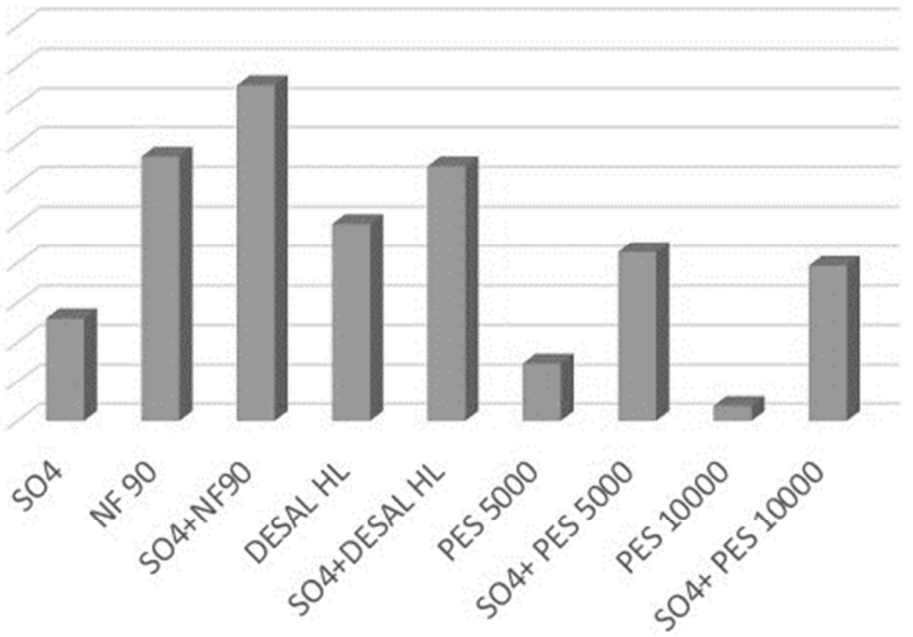

Fig. 4. DOC removal efficiency (\%) with single or combined treatment with Aluminiun sulphate coagulant $\left(\mathrm{SO}_{4}\right)$, nanofiltration and ultrafiltration membranes.

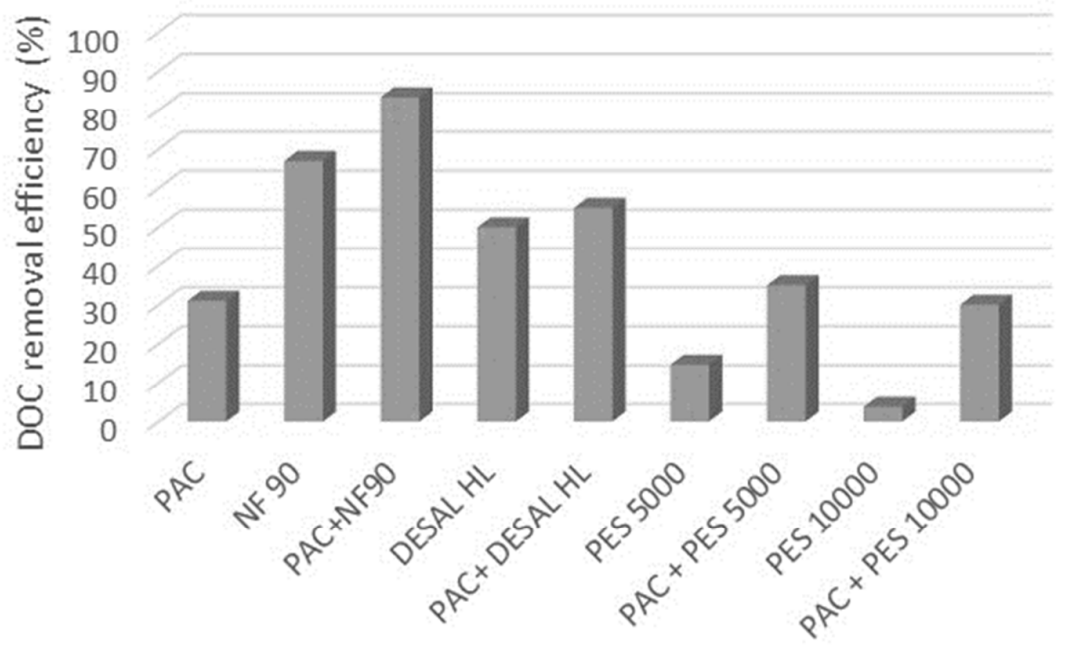

Fig. 5. DOC removal efficiency (\%) with single or combined treatment with PAC coagulant, nanofiltration and ultrafiltration membranes.

\subsection{Effect of single treatment on the formation of haloacetic acids}

Figure 6 shows the percentage reduction in the formation of HAAFP when the natural water of La Pedrera reservoir underwent a single treatment. 
Based on the coagulation experiments, increased efficiency in the reduction in HAAFP formation occurred after coagulation treatment with PAC (40\% yield), followed by treatment with the coagulant $\mathrm{Al}_{2}\left(\mathrm{SO}_{4}\right)_{3}$ (36\% yield) as compared with untreated water.

Several studies indicate that the organic matter that most affects the formation of HAAs is as follows: Hydrophobic acid>Hydrophilic acid matter>weak hydrophobic acids $>$ Hydrophobic neutral>hydrophobic bases, but it was worth noting that the specific HAAFP of weak hydrophobic acids is the highest followed by hydrophilic matter. In general, coagulation processes tend to eliminate higher percentages of organic matter with hydrophobic characteristics [26]. Zhao et al. (2013) [27] showed that for natural water treated with PAC, higher percentages of the fraction of weak hydrophobic acids were removed than in water treated with $\mathrm{Al}_{2}\left(\mathrm{SO}_{4}\right)_{3}$, and for both coagulants the hydrophilic material removed was lower than hydrophobic material. Hence, PAC treated water produces a greater reduction in HAAFP.

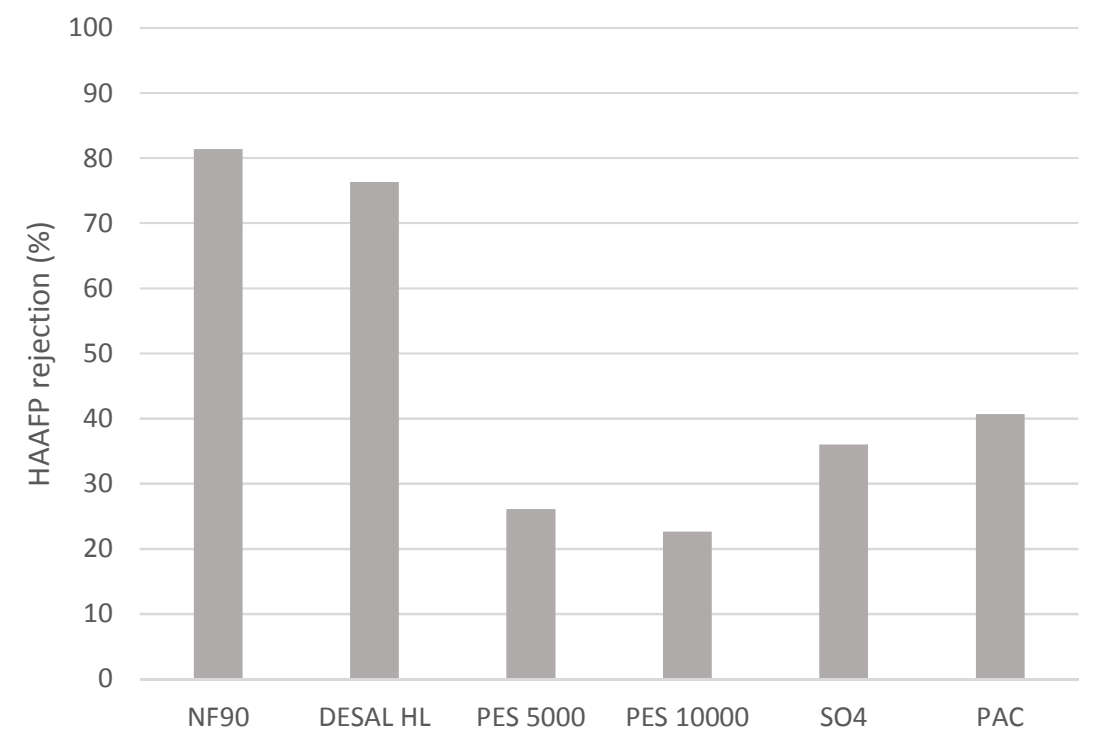

Fig. 6. Percentage reduction in the formation of HAAFP for single treatments.

Likewise, if the results obtained with a single membrane filtration treatment are analysed, it can be observed that the reduction in HAAFP with nanofiltration membranes is about $81 \%$ for NF90 and $76 \%$ for DESAL HL. On the other hand, in ultrafiltration membranes the reduction values of HAAFP are $26 \%$ for the PES 5000 membrane and $22 \%$ for the PES 10000 membrane, which are lower values than those obtained with coagulation treatment. This is mainly because the water treated in the 
present study has an increased hydrophilic matter presence with a low molecular weight that cannot be retained by ultrafiltration membranes, especially those of weak hydrophilic and hydrophobic characteristics. Therefore, yields obtained with ultrafiltration treatments were low. Tubić et al. (2013) studied the reduction of THMs and HAAs by coagulation; they obtained higher reduction rates when a mixture of $\mathrm{FeCl}_{3} /$ polyaluminium chloride (PAC) (30 mg FeCl $3 / \mathrm{L}$ and $30 \mathrm{mg}$ of $\mathrm{Al} / \mathrm{L}$ ) was used, obtaining a $56 \%$ removal in HAAFP. This value was $24 \%$ higher than when $\mathrm{FeCl}_{3}$ was used as coagulant [7]. Other authors found that the coagulation process can reduce haloacetic acid formation potential by 15\%-78\% [28]. Zhao et al. [27] 2013, indicated in their research that the reduction in THMFP and HAAFP by PACl under enhanced coagulation could reach $51 \%$ and $59 \%$, respectively, and the removal performance for $\mathrm{HAA}$ precursors by $\mathrm{PACl}$ was better than when $\mathrm{Al}_{2}\left(\mathrm{SO}_{4}\right)_{3}$ was used.

Figure 7 shows the concentration for each of the HAAFP found in the water samples which underwent a single treatment. Monochloroacetic acid was not detected. As can be seen in the chart for both natural and treated waters, the highest concentration obtained was for methyl dichloroacetate, followed by methyl dibromoacetate and methyl trichloroacetate, whereas the lowest concentration was for methyl bromoclhoroacetate. The compound values are clearly lower for the NF 90 membrane, resulting in an evident reduction in the concentration of methyl dichloroacetate.

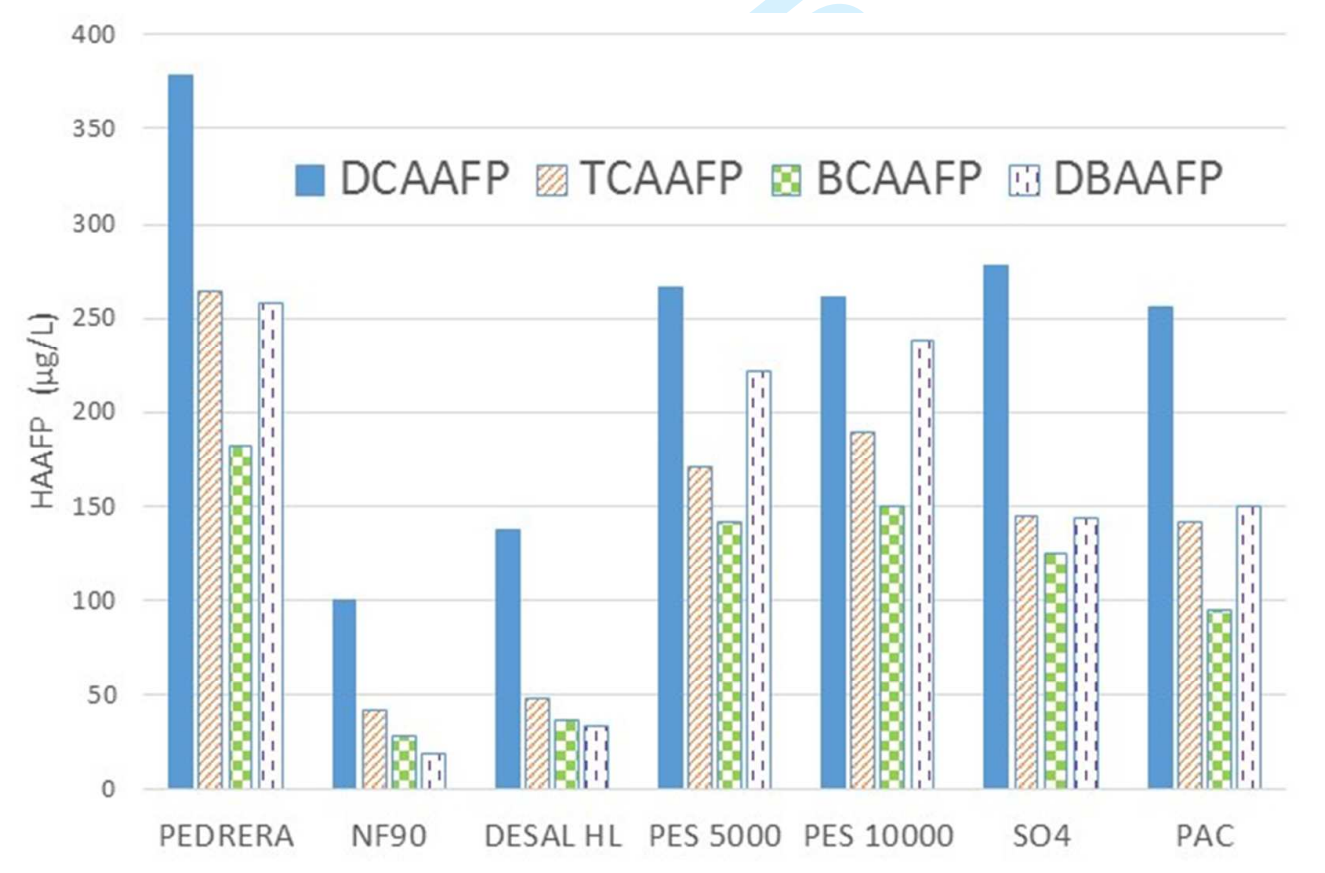


Fig. 7. Concentration of the different HAAFP detected for original water and water undergoing a single treatment (membrane filtration or coagulation).

\subsection{Effect of combination treatment on the formation of haloacetic acids}

Figures 8 and 9 show the reduction rates of HAAFP, for combined treatments of natural water from the water reservoir La Pedrera, initially treated with a coagulant followed by a membrane filtration treatment.

From the results, it appears that coagulation treatment followed by nanofiltration failed to significantly increase the reduction in the formation of HAAFP when PAC was used as a coagulant, yielding similar values to those of nanofiltration membrane treatment alone. Using $\mathrm{Al}_{2}\left(\mathrm{SO}_{4}\right)_{3}$ as a coagulant improved the reduction in HAAFP by combining this treatment with the NF 90 membrane by $4 \%$. The $\mathrm{Al}_{2}\left(\mathrm{SO}_{4}\right)_{3}$ coagulation treatment, followed by DESAL HL membrane, improved performance by $11 \%$, reaching in this case total yield values of $87 \%$.

However, significant changes can be observed in the case of combined treatment of coagulation followed by ultrafiltration. Ultrafiltration treatments alone yield values that do not exceed $26 \%$, although for the combined treatment of PAC+PES 5000 a yield of $65 \%$ is reached and $59 \%$ in the case of PAC+PES 10000. For $\mathrm{Al}_{2}\left(\mathrm{SO}_{4}\right)_{3}+\mathrm{PES} 5000$ and $\mathrm{Al}_{2}\left(\mathrm{SO}_{4}\right)_{3}+\mathrm{PES} 10000$ the yield reaches $80 \%$ and $37 \%$, respectively. This is a significant improvement, especially for the PES 5000 membrane combined with $\mathrm{Al}_{2}\left(\mathrm{SO}_{4}\right)_{3}$ coagulant, as these values are similar to those obtained with the NF 90 membrane but at much higher flow rates. This means a competitive advantage in the treatment due to the lower cost in the membrane filtration phase. Rakruam and Wattanachira (2014) [29], in their research, tested an in-line coagulation with a 40mg/L dosage of polyaluminium chloride on natural surface water and a subsequent treatment with a $0.1 \mu \mathrm{m}$ ceramic membrane, obtaining results of DOC and THMFP reduction slightly above $47 \%$ and $67 \%$, respectively. Their results also showed that this type of water treatment proved to be more effective in reducing the hydrophobic fraction than the hydrophilic fraction. 


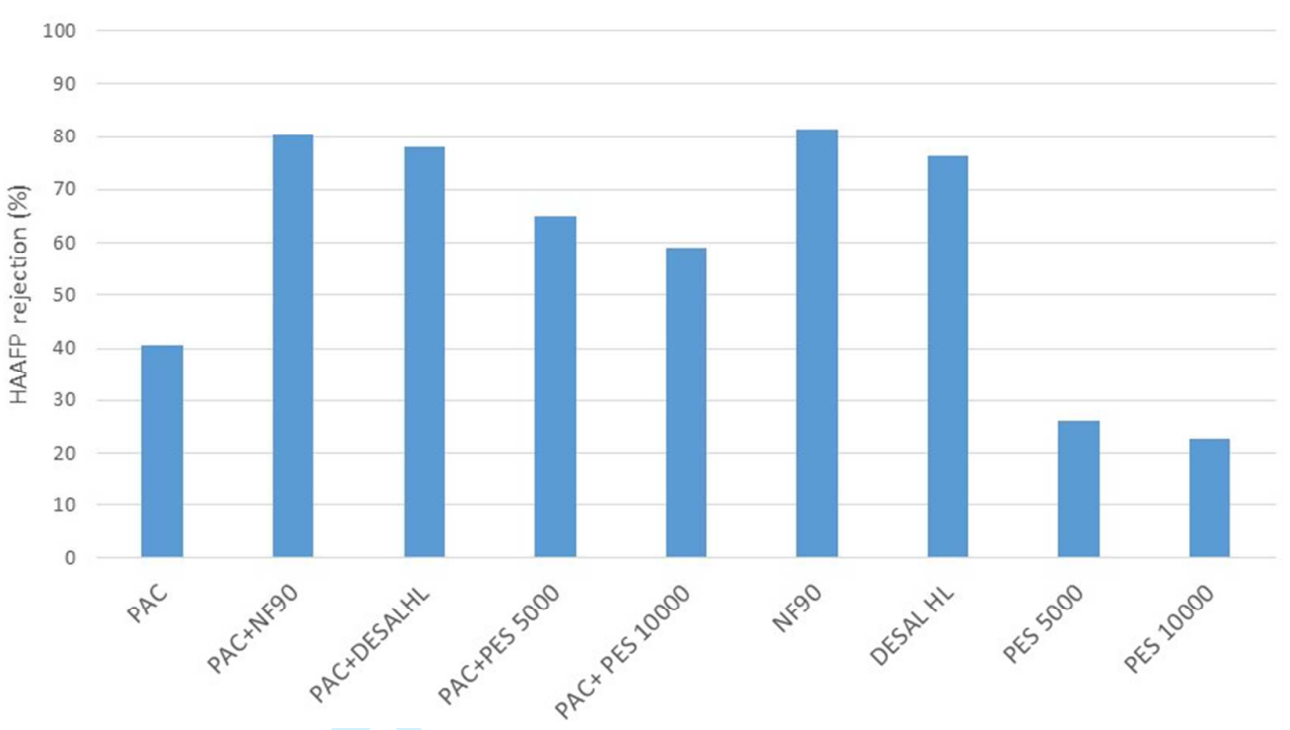

Fig. 8. HAAFP rejection as a function of combined treatment. PAC coagulation and membrane filtration.

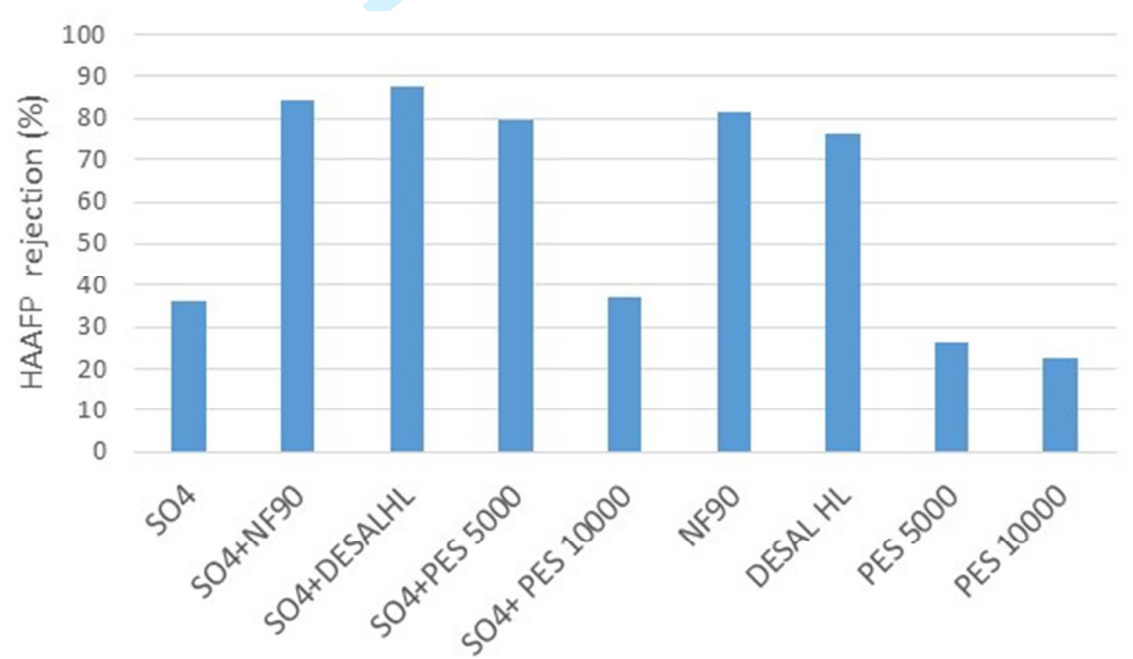

Fig. 9. HAAFP rejection as a function of combined treatment. $\mathrm{Al}_{2}\left(\mathrm{SO}_{4}\right)_{3}$ coagulation $\left(\mathrm{SO}_{4}\right)$ and membrane filtration.

\subsection{Effect on flow variation in the membrane filtration process}

Values of relative permeability ( $/ / \mathrm{Jo})$ as opposed to time are shown in figures 10,11 , 12 and 13 for each of the membranes studied. For each membrane, flow variation is shown for the water at La Pedrera without coagulation but before membrane filtration and with filtered water once it has been coagulated either with $\mathrm{Al}_{2}\left(\mathrm{SO}_{4}\right)_{3}$ or PAC. From these graphs, it can be deduced that in the process of ultrafiltration with the PES 5000 and PES 10000 membranes, the greatest flow reduction occurs for untreated water, 
reaching values of $11 \%$ for the PES 5000 membrane and $17 \%$ for PES 10000 . Pretreatment with $\mathrm{Al}_{2}\left(\mathrm{SO}_{4}\right)_{3}$ causes less flow loss in both cases. For both ultrafiltration membranes the lowest flow losses are obtained when coagulation with PAC precedes ultrafiltration. These data are consistent with the highest DOC removal with this pretreatment. Flow loss for both membranes when PAC pre-treatment is used is $5 \%$ approx.

In the case of nanofiltration membranes (figures 12 and 13), the flow loss is slightly higher than in the ultrafiltration membranes. When the water from La Pedrera reservoir was filtered with the DESAL HL membrane without previous coagulation, the flow loss was $19 \%$. In both membranes, pre-treated water generates a slightly lower flow loss. However, this is less significant than that observed in ultrafiltration membranes. For both membranes, the use of pre-treatment with coagulant PAC causes the lowest flow loss: for the DESAL HL membrane $10 \%$, for NF 90 it was $9 \%$.

Shuang Zhao et al. 2015 [30] studied the rejection of fulvic acid when they treated synthetic waters using coagulation treatment with Polyaluminium chloride followed by ultrafiltration process with $100 \mathrm{kDa}$ membranes. Their findings showed that the process of coagulation before ultrafiltration was capable of reducing membrane fouling by about $10 \%-20 \%$ approx. when compared with the decrease obtained with ultrafiltration treatment without previous coagulation. These differences depended on the dosage of coagulant used.

Xu et al (2015) worked on the impact of organic coagulant aids in synthetic waters. The effect on membrane fouling in a coagulation/ultrafiltration hybrid process was studied. The study shows that the flow reduction for conventional coagulation/ultrafiltration systems using aluminium coagulation is $52 \%$ approx., while the addition of polydimethyldiallylammonium chloride reduces this flow loss to $34 \%$ for ultrafiltration membranes with a MWCO of 100kDa [12]. 


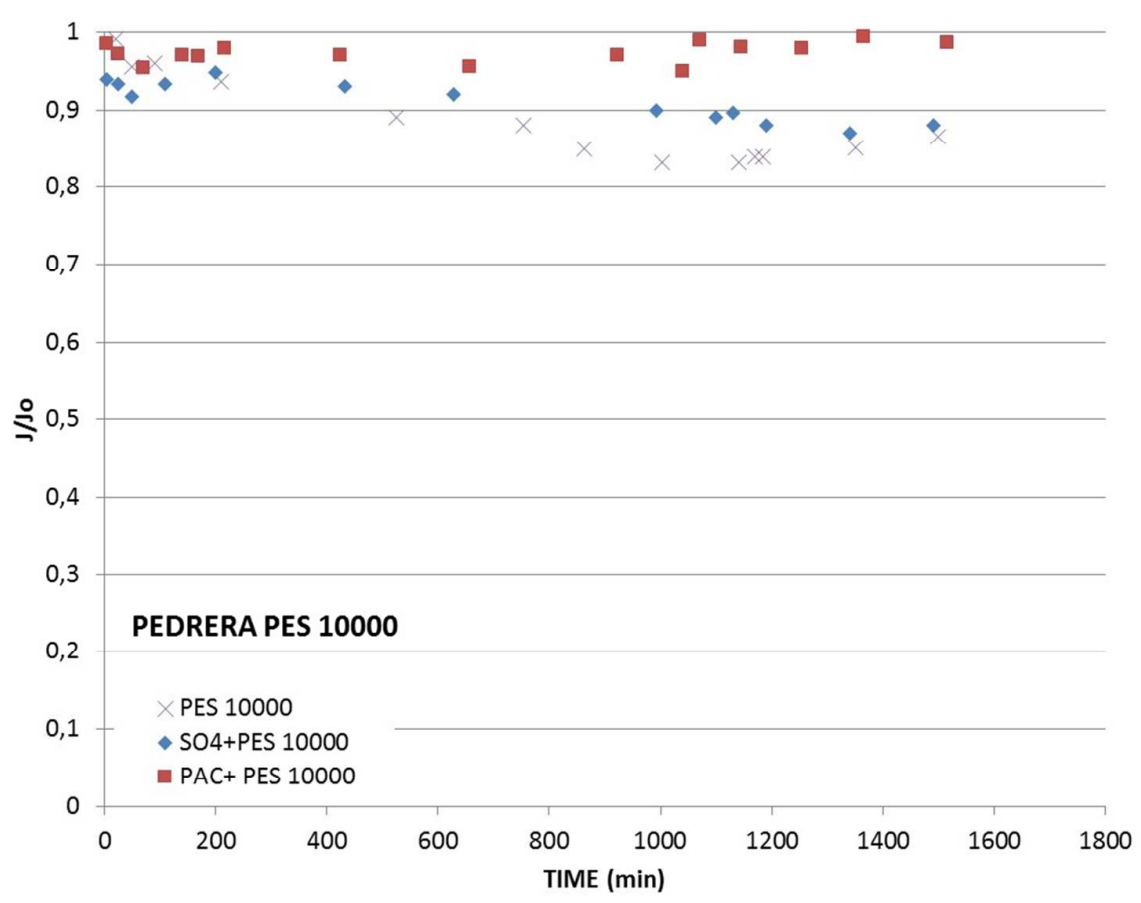

Fig. 10. Effect of coagulation on the relative permeability $(\mathrm{J} / \mathrm{Jo})$ of the ultrafiltration PES 10000 membrane as a function of time.

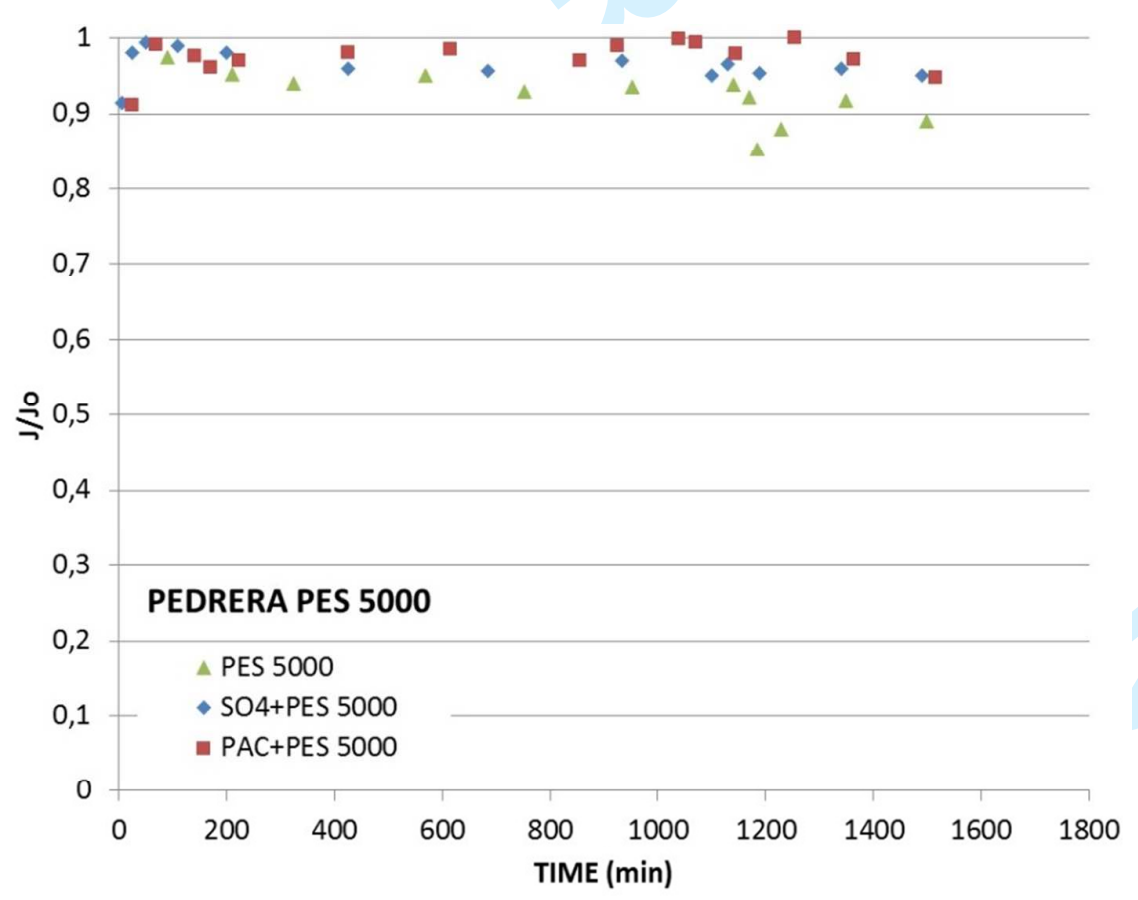

Fig. 11. Effect of coagulation on the relative permeability $(\mathrm{J} / \mathrm{Jo})$ of the ultrafiltration PES 5000 membrane as a function of time. 


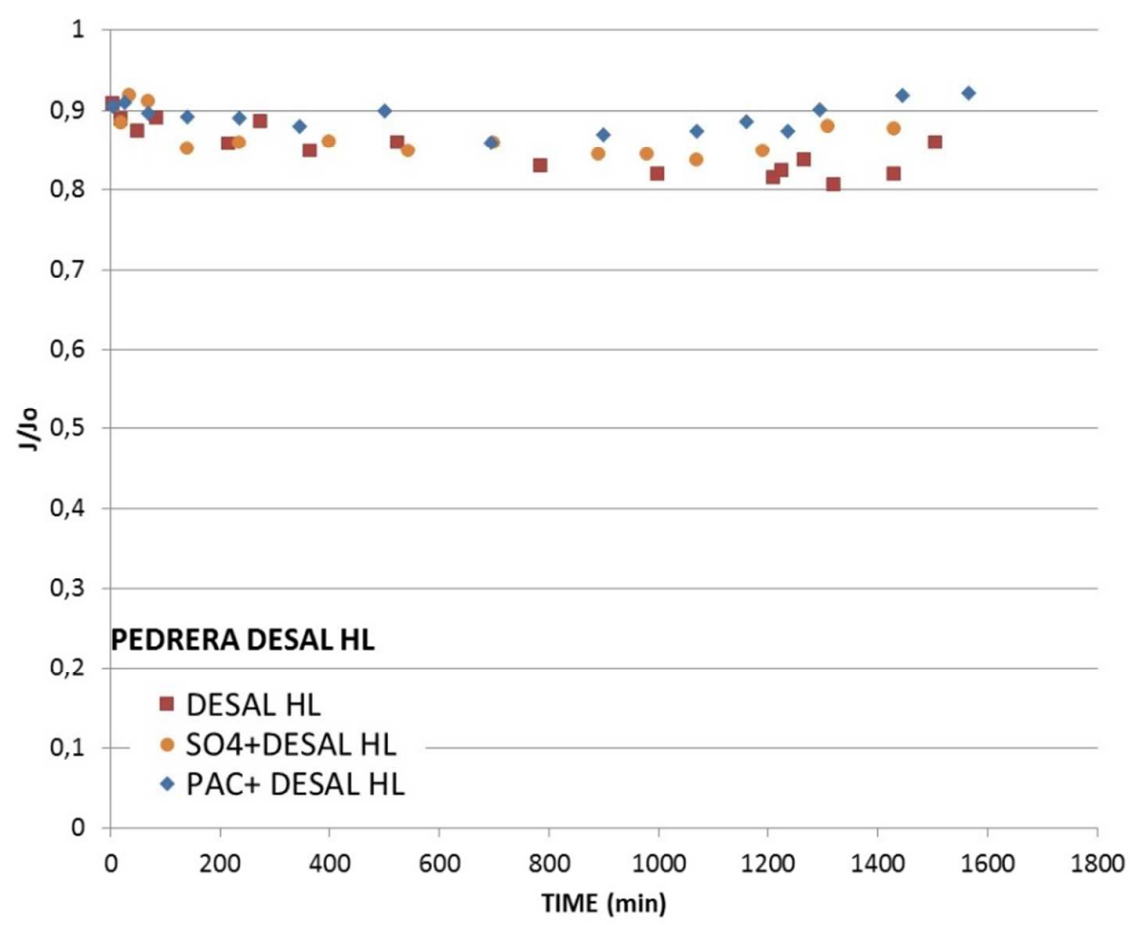

Fig. 12. Effect of coagulation on the relative permeability $(\mathrm{J} / \mathrm{Jo})$ of the nanofiltration DESAL HL membrane as a function of time.

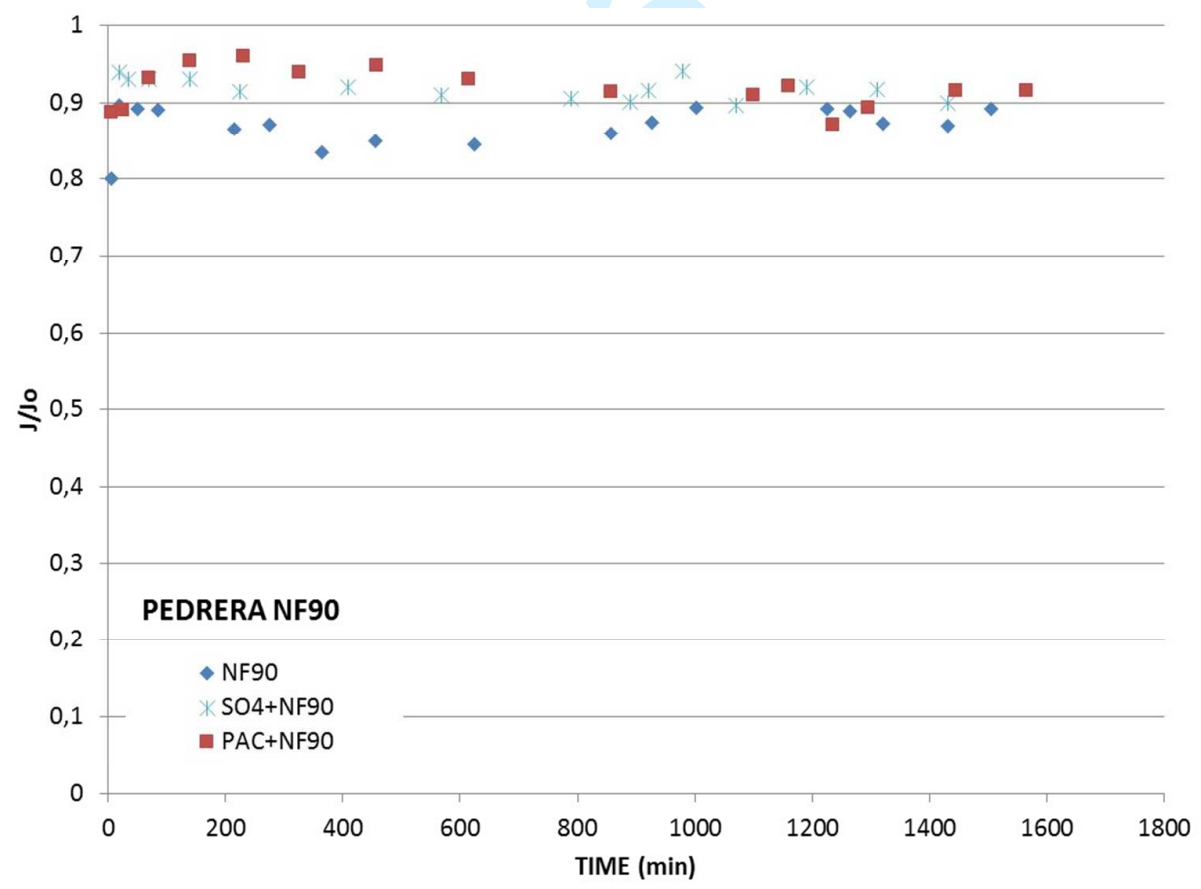

Fig. 13. Effect of coagulation on the relative permeability $(\mathrm{J} / \mathrm{Jo})$ of the nanofiltration NF 90 membrane as a function of time. 


\section{CONCLUSIONS}

Based on the experiments carried out, it can be concluded that the two nanofiltration membranes studied, NF 90 and DESAL HL, achieve better results in organic matter and HAAFP reduction than the ultrafiltration membranes PES 5000 and PES 10000.

In all cases, pre-treatment with coagulation improves DOC removal yields. Coagulation with PAC followed by NF 90 produces the best DOC rejection at $83 \%$ with optimum doses of aluminium. However, the flux of this membrane is low when compared with DESAL HL or ultrafilration membranes (PES 5000 or PES 10000).

Ultrafiltration or single treatment coagulation produced a very low rejection of HAAFP, which was always below $40 \%$. On the other hand, single treatment with the NF 90 filtration membrane produced a level of HAAFP rejection of $84 \%$ approx. However, the flux of this membrane was very low when compared with ultrafiltration membranes.

The lower production of HAAFP was achieved when the waters were treated with coagulant $\mathrm{Al}_{2}\left(\mathrm{SO}_{4}\right)_{3}$ followed by membrane filtration with the DESAL HL membrane ( $87 \%$ less). However, it is important to emphasize that in the treatment with aluminum sulfate followed by ultrafiltration with the PES 5000 membrane, the results for HAAFP rejection show values of $80 \%$ approx. These values are in the same order as those obtained with a single treatment with nanofiltration membranes. However, the flux of the PES 5000 membrane was 4,000 and 3,500 times higher than the flux obtained with the NF 90 and DESAL HL membranes, respectively.

\section{ACKNOWLEDGEMENTS}

The authors wish to express their gratitude to the Spanish Ministry of Economy and Competitiveness (CTM2013-46669-R "Combined treatments for degradation and removal of emerging contaminants in water") for providing financial support.

\section{REFERENCES}

[1] I. Delpla, T. Benmarhnia, A. Lebel, P. Levallois, M.J. Rodríguez, Investigating social inequalities in exposure to drinking water contaminants in rural areas, Environ. Pollut., 207 (2015) 88-96.

[2] H. Chen-Yan, Z. He-Zhen, L. Yi-Li, Z. Tian-Yang, Z. Fan, X. Bin, Dissolved organic matter fractions and disinfection by-product formation potential from major raw waters in the water-receiving areas of south-to-north water diversion project, China. Desal. Wat. Treat., 56 (2015) 1689-1697.

[3] J. Lu, T. Zhang, J. Ma, Z. Chen, Evaluation of disinfection by-products formation during chlorination and chloramination of dissolved natural organic matter fractions isolated from a filtered river water, J Hazard. Mater., 162 (2009) 140-145.

[4] W.D. King, L. Dodds, A.C. Allen, B.A. Armson, D. Fell, C. Nimrod, Haloacetic acids in drinking water and risk for stillbirth, Occup. Environ. Med., 62 (2005) 124127. 
[5] U.S. Environmental Protection Agency, Integrated Risk Information System, EPA 635/R-03/007, 2003, Washington, DC.

[6] M.K. Smith, J.L. Randall, E.J. Read, J.A. Stober, Teratogenic activity of trichloroacetic acid in the rat, Teratology, 40 (1989) 445-451.

[7] A. Tubić, J. Agbaba, B. Dalmacija, J. Molnar, S. Maletić, M. Watson, S. Ugarčina Perović, Insight into changes during coagulation in NOM reactivity for trihalomethanes and haloacetic acids formation, J. Environ. Manage., 118 (2013) 153-160.

[8] Q. Wang, Y. Ma, A. Li, J. Wang, R. Ma, Study on the removal of dissolved organic matters in the raw water by a new magnetic anion-exchange resin, Desal. Wat. Treat., 57 (2016) 572-581.

[9] E. Sperczyńska, L. Dąbrowska, E. Wiśniowska, Removal of turbidity, colour and organic matter from surface water by coagulation with polyaluminium chlorides and with activated carbon as coagulant aid, Desal. Wat. Treat., 57 (2016) 1139-1144.

[10] Y. Yoon, G. Amy, J. Cho, N. Her, Effects of retained natural organic matter (NOM) on NOM rejection and membrane flux decline with nanofiltration and ultrafiltration, Desalination, 173 (2005) 209-221.

[11] M. N. Abu Seman, D. Johnson, S. Al-Malek, N. Hilal, Surface modification of nanofiltration membrane for reduction of membrane fouling, Desal. Wat. Treat., 10 (2009), 298-305.

[12] W. Xu, Q. Yue, B. Gao, B. Du, Impacts of organic coagulant aid on purification performance and membrane fouling of coagulation/ultrafiltration hybrid process with different Al-based coagulants, Desalination 363 (2015) 126-133.

[13] L. Feng, W. Wang, R. Feng, S. Zhao, H. Dong, S. Sun, B. Gao, Q. Yue, Coagulation performance and membrane fouling of different aluminum species during coagulation/ultrafiltration combined process, Chem. Eng. J., 262 (2015) 1161-1167.

[14] Y. Wang, Q. Wang, B.Y. Gao, Q. Yue, Y. Zhao, The disinfection by-products precursors removal efficiency and the subsequent effects on chlorine decay for humic acid synthetic water treated by coagulation process and coagulationultrafiltration process, Chem. Eng. J., 193-194 (2012) 59-67.

[15] R. Bergamasco, L.C. Konradt-Moraes, M. Fernandes Vieira, M.R. FagundesKlen, A. Marquetotti Salcedo Vieira, Performance of a coagulation-ultrafiltration hybrid process for water supply treatment, Chem. Eng. J., 166 (2011) 483-489.

[16] M.R. Teixeira, M.J. Rosa, pH adjustment for seasonal control of UF fouling by natural waters, Desalination, 151 (2002) 165-175.

[17] K. Majewska-Nowak, I. Kowalska, M. Kabsch-Korbutowicz, Ultrafiltration of SDS solutions using polymeric membranes, Desalination, 184 (2005) 415-422.

[18] A. de la Rubia, M. Rodríguez, VM. León, D. Prats, Removal of natural organic matter and THM formation potential by ultra- and nanofiltration of surface water, Water Res., 42 (2008) 714-722.

[19] F.J. Rodríguez, Procesos de potabilización del agua e influencia del tratamiento de ozonización, Díaz de Santos S.A. Publishers, 2003.

[20] M. Kabsch-Korbutowicz, Effect of Al coagulant type on natural organic matter removal efficiency in coagulation/ultrafiltration process, Desalination, 185 (2005) 327-333. 
[21] Z. Yang, B. Gao, Q. Yue, Coagulation performance and residual aluminum speciation of Al2(SO4)3 and polyaluminum chloride (PAC) in Yellow River water treatment, Chem. Eng. J., 165 (2010) 122-132.

[22] D. Zheng, R. C. Andrews, S. A. Andrews, L. Taylor-Edmonds, Effects of coagulation on the removal of natural organic matter, genotoxicity, and precursors to halogenated furanones, Water Res., 70 (2015) 118-129

[23] A. Matilainen, M. Vepsäläinen, M. Sillanpää, Natural organic matter removal by coagulation during drinking water treatment: A review. Adv. Colloid Interface Sci., 159 (2010) 189-197.

[24] Y. Wang, R. Mao, Q. Wang, Z. Yang, B. Gao, Y. Zhao, Fulvic acid removal performance and control of disinfection by-product formation potential in coagulation-ultrafiltration process, Desalination, 302 (2012) 55-64.

[25] Q. Xiangli, Z. Zhenjia, W. Nongcun, V. Wee, M. Low, C.S. Loh, Ng T. Hing, Coagulation pretreatment for a large-scale ultrafiltration process treating water from the Taihu River, Desalination, 230 (2008) 305-313.

[26] D. Gang, T.E. Clevenger, S.K. Banerji, Effects of Alum Coagulation on Speciation and Distribution of Trihalomethanes (THMs) and Haloacetic Acids (HAAs), J. Environ. Sci. Health, Part A, 40 (2005) 521-534.

[27] Y. Zhao, F. Xiao, D. Wang, M. Yan, Z. Bi, Disinfection byproduct precursor removal by enhanced coagulation and their distribution in chemical fractions, J. Environ. Sci., 25 (2013) 2207-2213.

[28] P. C. Singer, K. Bilyk, Enhanced coagulation using a magnetic ion exchange resin, Water Res., 36 (2002), 4009-4022.

[29] P. Rakruam, S. Wattanachira, Reduction of DOM fractions and their trihalomethane formation potential in surface river water by in-line coagulation with ceramic membrane filtration, J. Environ. Sci., 26 (2014) 529-536.

[30] S. Zhao, B. Gao, S. Sun, Q. Yue, H. Dong, W. Song, Coagulation efficiency, floc properties and membrane fouling of polyaluminum chloride in coagulationultrafiltration system: The role of magnesium, Colloids and Surfaces A: Physicochem. Eng. Aspects, 469 (2015) 235-241. 